\title{
UAV, Digital Processing and Vectorization Techniques Applied to Building Condition Assessment and Follow-up
}

\author{
Carles Serrat*, Sebastian Banaszek, Anna Cellmer, Vicenç Gibert, Anna Banaszek
}

\begin{abstract}
The aim of the paper is to explain the basic principles of carrying out an inventory and follow-up of buildings and their condition assessment, by using the Full Interactive Visualization Method for Building Condition Assessment platform. It is a platform enabling the implementation of construction inventory based on the remote cooperation of many specialists in the field of, among others: building construction, architecture, civil engineering, photogrammetry, CAD, UAV. This type of cooperation is of particular importance especially in the context of the current epidemiological situation related to COVID-19. The idea of the presented platform fits into the broadly understanding of Building Information Modeling. After introducing the methodology, stages of the inventory and follow-up process carried out within the platform are illustrated and discussed on the basis of a case study. Based on the obtained results it can be concluded that the proposed methodology creates a convenient, efficient and inexpensive tool for massive inspection of building resources in large areas. The inventory is based primarily on high-quality photo and video material obtained from the deck of an unmanned aerial vehicle and the expert knowledge of the inspector conducting the inspection. By combining digital images data (photos, 3D model, orthophotos) with substantive data (facade element classification tables, wear / defect classification tables), we get a platform that allows intuitive access to viewing, classification, editing and analysis of selected data.
\end{abstract}

Keywords: BIM; building condition assessment; GIS; monitoring; UAV

\section{INTRODUCTION}

Innovative technology applied to building condition assessment should be flexible, achievable, reliable, accessible, updating data and ensuring stakeholder participation. An example of this direction is the use of digital technologies, especially in the field of the use of unmanned aerial vehicles (UAVs) in order to improve inventory activities and improve the work of an inspector, in particular when assessing the technical condition of buildings. The idea presented in the article concerns the Full Interactive Visualization Method for Building Condition Assessment platform and is part of the broadly understood Building Information Modeling. As a real-time capturing of data technology, UAV is used in the construction industry. In the recent years, the UAVs have been successfully used for different construction and operation applications of various types of construction projects [1].

The use of unmanned aerial vehicle technologies to efficiently collect information for effective updating of Building Information Modeling, building management and documentation is a topic that is being studied and considered in terms of systematic use by various authors [2-4].

The main aim of this paper is to introduce the further research about the tool previously introduced by Banaszek et al. (2019) [5] for the accurate assessment of the technical condition of buildings, as an efficient strategy for the massive inspection of building stocks, in big residential areas. The development of the Full Interactive Visualization Method for Building Condition Assessment platform (IVP4BCA) [5] requires the selection of technical measures of data collection and computational methods of data processing (including software) as well as the requirements for cooperation of many specialists:

- Inspector - a specialist in the field of construction thanks to the use of modern technologies integrated through the described platform in the inventory process, the Inspector does not have to carry out a personal inspection in the field, thanks to this solution the labor intensity of a single process decreases and the Inspector's efficiency increases. Responsible for indicating the building and making its inventory.

- The operator of an unmanned aerial vehicle (UAV) - a specialist in piloting unmanned aerial vehicles and photogrammetry - in the proposed solution, he is the only person whose presence is required at the inventory site. In the future, when Beyond Visual Line of Sight (BVLOS) flights become commonplace, it will be possible to reduce the need for field visits also for the UAV operator. Responsible for the planning and execution of the raid and the quality of the obtained material.

- Photogrammetrist - specialists in the field of data processing and analysis, responsible for data processing, generating products and assessing their accuracy.

- Computer Aided Design (CAD) operator - a specialist in the field of CAD software, responsible for generating a square grid and classifying building elements subject to inventory.

The paper is organized as follows. In chapter 2 it will be shown the main methodology illustrated by the 3D model as well picture of the all building its facades and roof in flat form. Chapter 3 contains description of the case study. The final product is influenced by the requirements regarding the detail of image geoinformation necessary for analysis and the area of inspection as a factor in the time of execution of planned works. Further results and discussion will compose chapter 4 . The paper ends with a summary of the main conclusions.

\section{METHODOLOGY}

As an important means of obtaining spatial data, the unmanned aerial vehicle (UAV) remote sensing has such advantages as real-time, flexible high-resolution and cost- 
effectiveness [6]. The type and quality of the data obtained using UAVs depends largely on installed on them sensor, camera resolution, the technical capabilities and planning of photogrammetric flights [7]. The flight mission of the UAVs must be technically protocolized in order to get the proper high-quality information about the real condition of the building [8].

Based on that, the following methodology for the implementation of the inventory based on the platform is proposed, which is used for building condition assessment:

- Indication of the object for inventory - building inspector.

- Analysis of the legal situation in the area designated for the inventory - UAV operator.

- Analysis of the field situation in the area intended for inventory - UAV operator.

- Development of a raid plan - UAV operator.

- Implementation of the raid - UAV operator.

- Analysis of the quality of the obtained material photogrammeter.

- Digital processing, generation of orthophotos and a 3D model - photogrammeter.

- Analysis of the accuracy of the generated orthophoto planes - photogrammetry.

- Generating a square grid - CAD operator.

- Classification of object elements - CAD operator.

- Visual inventory - Building inspector.

Fig. 1 illustrates in detail the IVP4BCA steps. The methodoly is empowered by the results of processing data obtained from the board of the unmanned aerial vehicle. The data is acquired using an RGB sensor, and then, using the Pix4D class software, processed into orthophotos, point clouds and a 3D model. The processing is an iterative process, usually requires 2 to 4 iterations. The first iteration is performed in an unattended process. Materials that are created as a result become the basis of which the obtained data and its completeness are assessed. In the second iteration, the supervised process removes excess data and visible artifacts. After reprocessing, the geometry is analyzed, and the generated materials are visually assessed. If the results of the test are satisfactory, the materials are imported into IVP4BCA, otherwise an iterative process takes place in order to eliminate the observed errors in the geometry and the visual side of the materials.

More specifically, all digital images obtained from the unmanned aerial vehicle deck are geotagged. In order to be able to indicate the location of images on orthophotoplan in open-source GIS software [9], you must first extract the coordinates from the EXIF data of each of the digital images. This can be done with any software that enables batch reading and saving of EXIF data to a .txt file or use the option to import coordinates of processed images in the application used for data processing and generating orthophotoplans.

After importing the materials (orthophotos, cloud point, 3D model, photos etc.), selection of the size of the square grid that will be used for further analysis is needed. In order to properly select its size, it is necessary to carry out a visual analysis of the facade and its parts classification. In the next stage, the damage is visually assessed with selection of analytical algorithms.
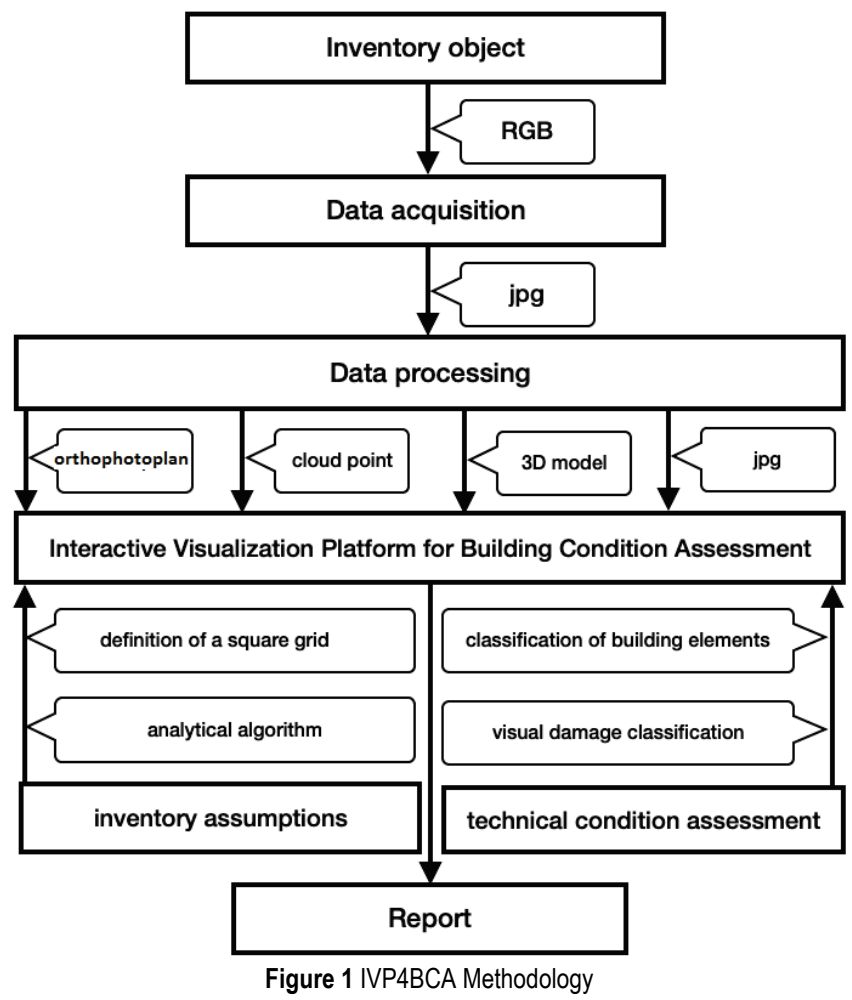

At the end, a report is generated, which, as a document signed by the Building Inspector, may be an element of the documentation from the course of the inspection.

Research results [7] showed that the UAVs orthophotos satisfactorily passed the spatial quality tests. Assessment of the influence of UAV image quality on the orthophoto production presented in such articles as $[8,10]$. The tested area covered urban, flat, agricultural and woodland terrains.

In recent years, researches have proposed building damage detection algorithms using remote sensing technology. 3D building damage detection and urban structural damage methods using UAV images described in the research of [11-13]. The results show that geometric parameters derived from the $3 \mathrm{D}$ point cloud can reveal damage indicators that are difficult to detect in the original imagery.

\section{CASE STUDY}

A residential building located in Olsztyn et al. Grunwaldzka. (Poland) was indicted to carry out the inventory. The building is owned by the Commune and is managed by the Board of Municipal Buildings in Olsztyn. The building is situated on a small plot additionally developed with outbuildings. The building is three-story, Lshaped and covered with a two-pitched roof. It was built in the 1960s. Despite proper renovation management, the building shows signs of technical wear, especially in terms of façade wear. 
For the purposes of the UAV raid, the operator conducted an analysis of the aviation legal situation in the area designated for the inventory.

The analysis of the field situation in the area intended for the UAV raid showed that the inventoried object is located in a compact urban development, on both sides directly adjacent to the road lane. An additional obstacle is the narrow sidewalk adjacent to the building, about $1.5 \mathrm{~m}$ wide, and a two-way road, about $9 \mathrm{~m}$ wide, on which there is traffic, including public transport buses. In the off-peak hours, pedestrian traffic can be considered as low-intensity and vehicle traffic moderate.

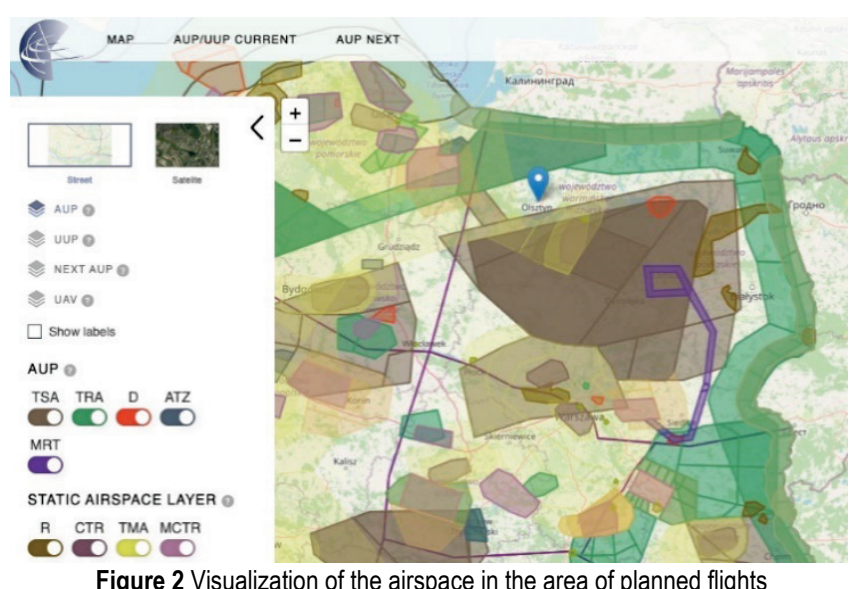

Figure 2 Visualization of the airspace in the area of planned flights

When developing the flight plan, the position of the sun in relation to the inventoried object was taken into account. The order of the façade inventory was planned in such a way that it was properly illuminated during the raid.

The take-off and landing sites are designated separately for each elevation. When planning the flight, attention was also paid to the difficult accessibility of one of the elevations. The flights were carried out using the DJI Inspire One drone. It is a drone with a weight not exceeding $3.5 \mathrm{~kg}$ MTOM, classified in the MR (multirotor) category in the so-called the $\mathrm{X} 4$ system. The camera installed on board the drone is X3 ZENMUSE with a 12 Mpix matrix with a size of $4000 \times 3000$ Pix. 7 flights ( 6 facades + roof) have been planned. Flights for the façade inventory were carried out in manual mode using the native DJI GO drone control application. The roof inventory was carried out in automatic mode, using the DJI GS application for photogrammetric flights. All flights are to be carried out as Visual Line of Sight (VLOS) flights, in accordance with the diagram shown in Fig. 3. Design coverage of $\min .80 / 80 \%$, distance from the facade approx. 2 $\mathrm{m}$, height above the roof level approx. $10 \mathrm{~m}$. Shutter release manually or with an interval - 2 seconds. GSD is planned at the level of $<0.5 \mathrm{~cm}$.

The flight was carried out at high humidity and transient slight rainfall, the temperature was about +5 degrees, wind at about $5 \mathrm{~m} / \mathrm{s}$ (in gusts up to $10 \mathrm{~m} / \mathrm{s}$ ). At the stage of the raid implementation, changes were made to its implementation consisting in a change in the number of take-off points finally, the inventory of the building was made from 3 positions. Due to the distance from the neighboring building not exceeding $2 \mathrm{~m}$, the material for the north-west façade was obtained only from diagonal raids carried out at large angles to the wall plane. Interval release shutter.

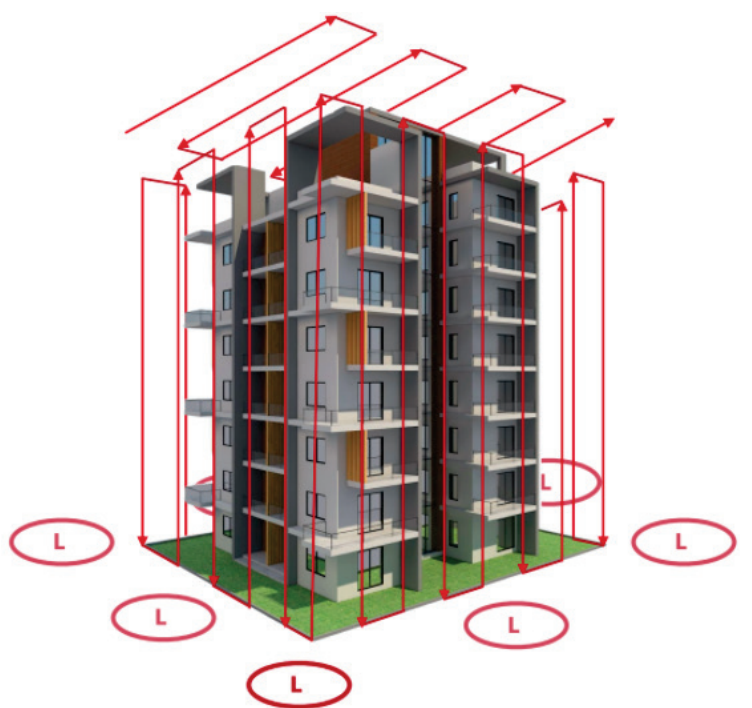

Figure 3 Design of a manual cubature raid for the building inventory (landing strip)

\subsection{Digital Processing, Ortofhotoplans Generation and 3 D Model}

As part of the inventory, a total of 818 good quality .jpg photos were obtained. The photos were properly exposed, lacking high contrast in shadows and highlights and sharp. Despite the fact that the flight was carried out manually, all the photos were calibrated, and the assumed for coverage and resolution were achieved $(\mathrm{GSD}=0.36 \mathrm{~cm})$.

The Pix4D mapper software was used to generate orthophotos of the elevation and the 3D model, the preprocessing on a PC (i7-2600 CPU @ 3.40GHz; RAM: 16GB; GPU: NVIDIA GeForce GTX 750) took almost 7 hours. The data was processed in the UTM zone $34 \mathrm{~N}$ (egm96) coordinate system. As a result of this process, a point cloud was created, represented by $120052712 \mathrm{D}$ key points ( 3676 $5553 \mathrm{D}$ points) with a mean reprojection error of 0.278 pixels. Such a result allowed to obtain a median number of points per 1 photo at the level of: 24724 for $2 \mathrm{D}$ points and 13924 3D points.

Due to the GPS signal disturbances occurring during the raid, the data was processed in two blocks:

- Block I included the following elevations: south-west, west, north-west, north-east and a roof.

- Block II included the south-eastern elevation.

To align the blocks, it was necessary to enter the 11 manual tie point and reprocess the data. After these activities, the cloud was generated in one block, the inventoried object was characterized by the correct geometry, shape and proportions. Finally, the relative camera position and orientation of the uncertainties $X, Y, Z$ was obtained at $<0.025$ for mean and $<0.015$ for sigma.

In order to generate a 3D model devoid of artifacts, it was necessary to carry out manual cleaning and classification of 
the point cloud (Fig. 4 and Fig. 5). The process took almost 6 hours and resulted in the generation of a model practically free from contamination. The model allows it to be used for the visualization of selected, inventoried phenomena in $3 \mathrm{D}$ space in a natural way for the user. The carried-out process of cleaning the point cloud additionally influenced the quality of the generated orthophotoplanes of the facade and roof. As part of this stage, an orthophotoplan separation was generated for each of the elevations (Fig. 6).



Figure 4 Visualization of the generated model in 3D space

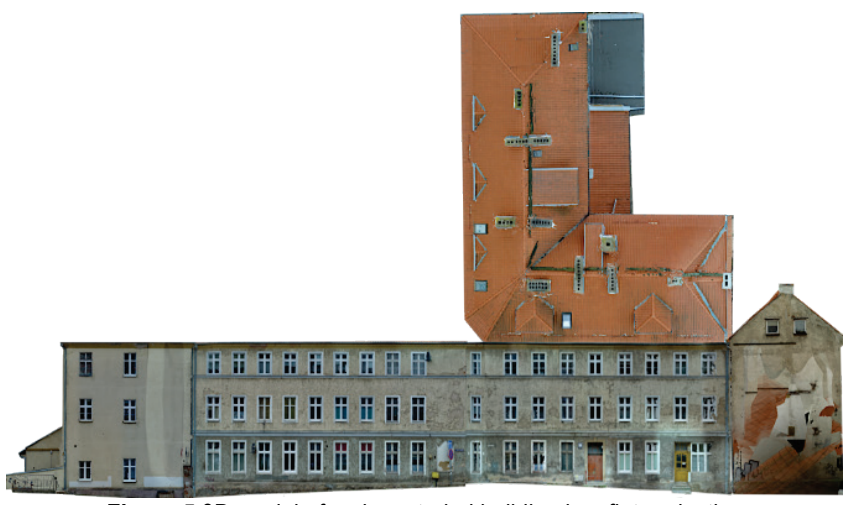

Figure $53 \mathrm{D}$ model of an inventoried building in a flat projection

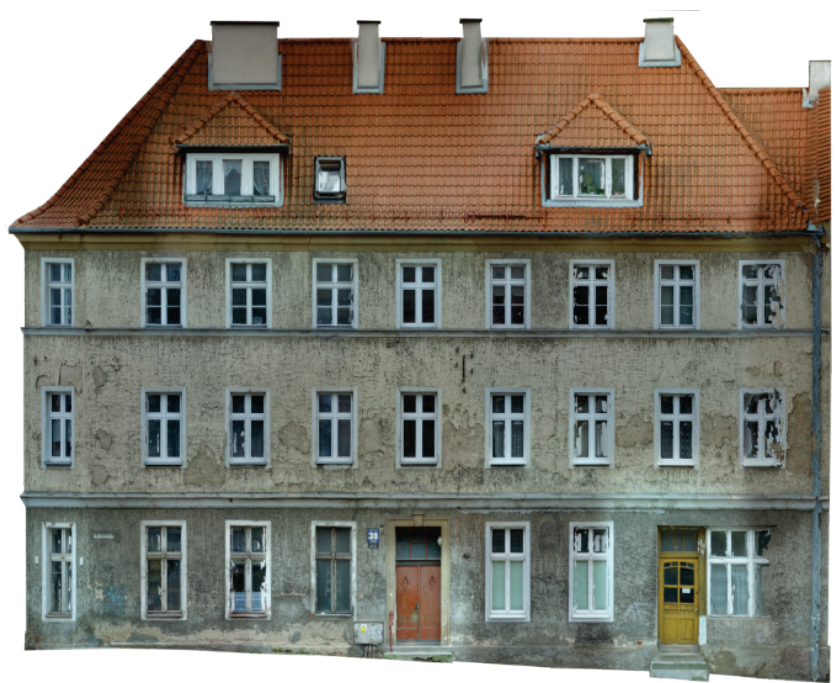

Figure 6 Ortofhotoplan of North-East elevation

\subsection{Accuracy Analysis of Generated Ortophotoplans}

Work on orthoplanes takes place in a local system, the accuracy of the GPS module used for geotagging photos (accuracy of determining the position $\pm 2.5 \mathrm{~m}$ ), which is standard UAV equipment, does not affect the usability of the generated material. In the local system, the distortion recorded inside the system is important, and not the external error of the point position in the selected coordinate system (UTM zone 34N). Due to the above, the quality of the generated orthophotoplanes is described by the GSD coefficient, which is $0.36 \mathrm{~cm}$, and the length measurement error, which is $0.50 \mathrm{~cm}$. The length measurement error was determined by performing control measurements on an inventoried object using the Leica Disto D810 laser rangefinder. For the control purposes, about 50 measurements were made in different planes.

\subsection{Generation of a Square Grid and Classification of Building Elements}

In order to additionally view the selected image directly from the GIS application by indicating its center, the abovementioned data should be enriched with the path to the directory in which the images will be ultimately stored. The easiest way to do this is to use batch directory inventory software that saves data most often in a .txt file in the form of an absolute path "c: / project / image.jpg" or the relative "... project / image.jpg". Thanks to the possibilities offered by today's spreadsheets, you can easily combine the contents of both files and generate a .txt or .csv file with the structure: "Filename.jpg [Tab] $X$ coordinate [Tab] $Y$ coordinate [Tab] $Z$ coordinate $[\mathrm{Tab}] \mathrm{c}$ : / design / name.jpg ". A file prepared in this way, imported into the GIS software, after indicating columns containing the selected coordinates, enables visualization of image centers and preview of images directly from the application without the need to know their physical location.

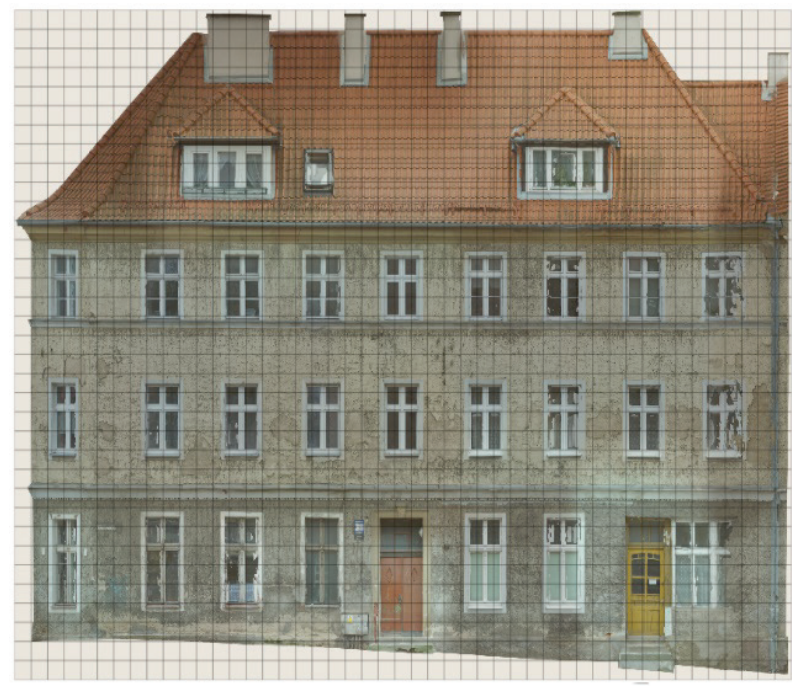

Figure 7 Orthophotoplan with a squared grid 
In the case of visualization of images in the orthophotomap area, we use the $X, Y$ coordinates, in the case of orthophotos of elevations (orthophotos the façade) vertical $Z, Y$. The experiment generated a file consisting of 926 records, containing 5,556 attribute values.

The next step to assign specific values of selected attributes for a previously defined part of the facade is to create a matrix of squares of the selected size and size.

Based on the conducted analyses, a matrix made of squares with a side of $0.4 \mathrm{~m}$ was considered optimal (Fig. 7).

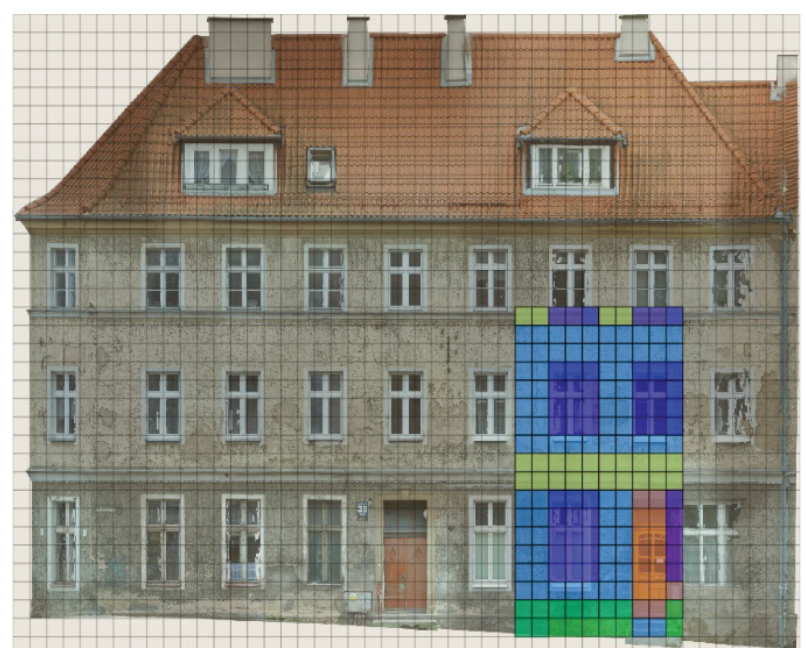

Figure 8 Ortophotoplan with completed qualification of inventoried elements

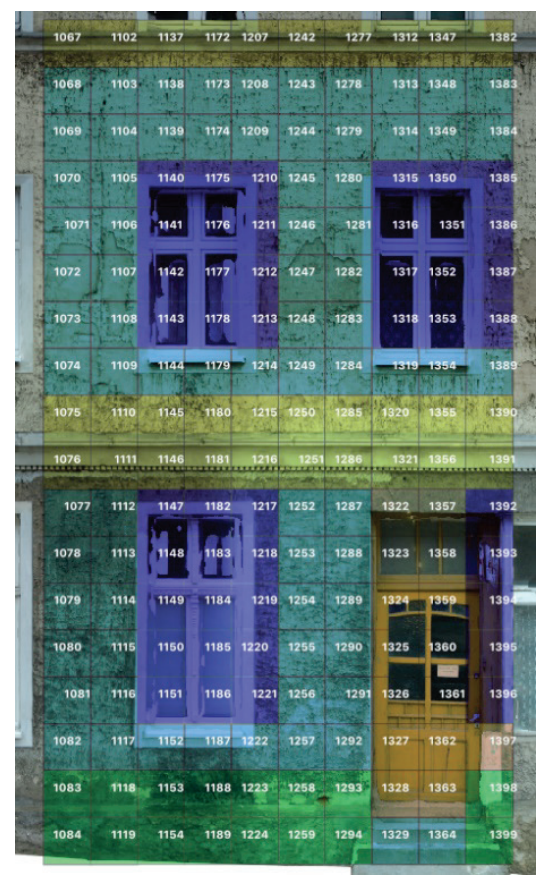

Figure $9 \mathrm{~A}$ fragment of the orthophoto plan with the performed qualification of the inventoried elements

The basic elements of the façade classified in the manual process include, first of all, the geometry of the façade and the roof, window and door joinery and architectural details (Fig. 8 and Fig. 9). Depending on the assumed accuracy of the final inventory of the above-mentioned elements can be subjected to classic polygon vectorization (for the most accurate inventories) or indicated by assigning individual mesh squares a value corresponding to the inventoried elements (for the inventory requiring less accuracy). In our case, method 2 was used, for the needs of which 5 classes of elements they were created: 1 - wall, 2 - molding, 3 - window, 4 - plinth, 5 - door (Fig. 10).

\begin{tabular}{|c|c|c|}
\hline Etykieta & & Reguta \\
\hline$v$ & Fasade & "_Fasade" = 1 \\
\hline$\checkmark$ & Wall & "Wall" = 1 \\
\hline v & Door & "_Door" = 5 \\
\hline$\checkmark$ & Window & "_Window" = 3 \\
\hline v & Plinth & "_Plinth" = 4 \\
\hline$\checkmark$ & Molding & "_Molding" = 2 \\
\hline
\end{tabular}

Figure 10 List of classes of identified facade elements

The matrix was created in 2 stages. The first stage consisted of creating a square grid using the QGIS tool: vector / research tools / create a grid, resulting in a linear vector layer. In the second stage, linear objects were transformed into polygonal objects using the tool: vector / geometry tools / lines into polygons. As a result, an attribute table was created with the number of records equal to the number of polygons. A total of 1,645 polygons were generated based on the created $47 \times 35$ matrix. At this stage, the table contained only 5 attributes: polygon ID and top, down, left, right - coordinates of the polygon corners.

\subsection{Visual Inventory}

The last step is to carry out a visual assessment of the technical condition of the facade by the inspector, determining the degree and type of wear on the basis of orthophotoplanes based on a square grid and classification (Fig. 11). Its implementation enables the automatic visualization of wear in accordance with the indicated criteria and the determination of the area and position of each type of defects found (Fig. 12 and Fig. 13).

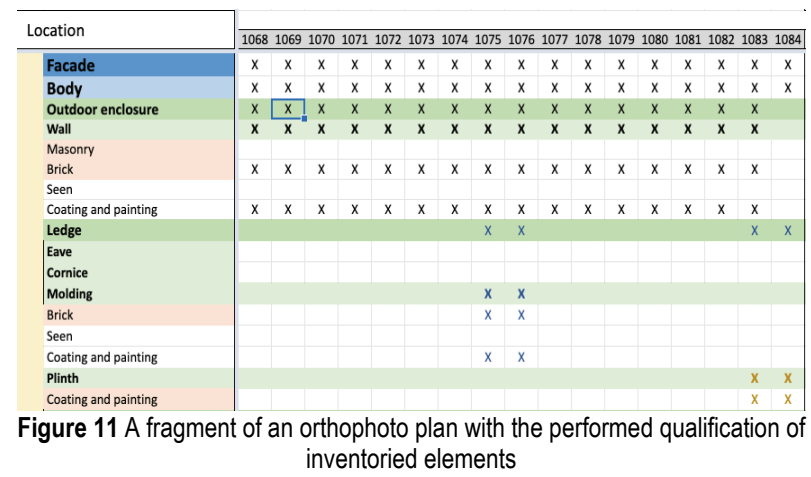

In order to enter data obtained during manual examination of generated orthophotoplans, the attribute table was expanded with another 138 attributes, for which the values found were then introduced. As a result, it became possible to conduct surface analyzes of the façade's technical condition both on the basis of entered, directly observed 
attribute values and using any combination of their values using the so-called GIS application available in the GIS application called field calculator.
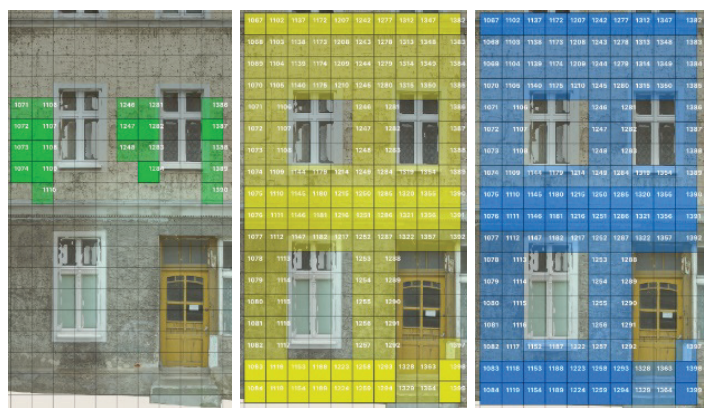

Figure 12 Visualization of a specific degree of wear, depending on the type found

\begin{tabular}{|c|c|c|}
\hline \multicolumn{3}{|c|}{$\checkmark \checkmark \circlearrowleft$ siatka40x40 } \\
\hline & $\mathbf{v}$ & Capillary moisture/Total2 \\
\hline & $\mathbf{v}$ & Capillary moisture/Local2 \\
\hline & v & Capillary moisture/Tocal3 \\
\hline & $\checkmark$ & Chipping/Puntual \\
\hline & 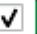 & Chipping/Local \\
\hline & 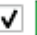 & Chipping/Total \\
\hline & $\boldsymbol{v}$ & Soiling/Total1 \\
\hline & $\checkmark$ & Soiling/Total2 \\
\hline & $\mathbf{v}$ & Soiling/Total3 \\
\hline
\end{tabular}

Figure $13 \mathrm{~A}$ fragment of the list of inventoried types of use

\section{CONCLUSION}

The proposed Full Interactive Visualization Method for Building Condition Assessment is based primarily on highquality digital information obtained from the deck of an unmanned aerial vehicle and the expert knowledge of the inspector conducting the inspection. By combining digital images and geoinformation data (photos, 3D model, orthophotos) with substantive data (facade element classification tables, wear / defect classification tables), we get a platform that allows intuitive access to viewing, classification, editing and analysis of selected data:

- 3D module - enables the visualization of selected, inventoried phenomena in 3D space in a natural way for the user and is most often used to carry out inspections and move around the model;

- 2D module - allows you to visualize selected, inventoried phenomena in $2 \mathrm{D}$ space in a way that enables their identification, location and accurate measurement.

Factors that have a negative impact on the efficiency of the proposed methodology for Building Condition Assessment should be mentioned.

The first group of factors is related to UAV technology:

- The possibility of flying depends on the weather - in some cases it is impossible to carry out tasks in accordance with the previously agreed schedule. It becomes especially visible in the autumn and winter period;

- Obtaining the required permits for flights from the property owner or manager - not everyone understands the nuisance associated with the implementation of flights within their property.

The second group is related to digital processing:

- Large volume of acquired material - gigabytes of acquired data require storage, processing, analysis and archiving, for which an efficient, stable and highcapacity Network Attached Storage (NAS) system is needed;

- High hardware requirements for the proper operation of data processing software (obtained from UAV) currently used processing algorithms cause that data processing processes are often processes lasting many hours, and the prices of the appropriate class of computer equipment make it difficult to implement the so-called parallel processing.

- Imperfection of automatic data processing algorithms orthophotos, point clouds and 3D models generated in an unattended process contain many artifacts. Therefore, removing them in a supervised process requires a large amount of time by a specialist.

After considering the above-mentioned limitations based on the conducted research, it can be concluded that the proposed methodology creates a convenient and efficient tool for massive inspection of building resources in large areas. The use of the described platform in the inventory process enables the optimization of the work of human resources involved in the implementation of the process, especially in relation to the construction inspector, who can carry out his activities without the need to visit inventoried facilities each time, thanks to which the costs of logistics and time lost on commuting are eliminated.

Creation of a platform based on the proposed methodology will allow to provide users with the use of a modern tool enabling full integration of the construction inventory process with BIM.

By optimizing the work of the task force, it is possible to lead to a situation in which the inspector's work will be carried out completely online from the office.

\section{Notice}

The paper was presented at PBE2020 - International Scientific Conference "People, Buildings and Environment 2020". The $14^{\text {th }}$ conference was held in the Rožnov pod Radhoštěm city, the Czech Republic, from 7 to 9 October 2020. The paper will not be published anywhere else.

\section{REFERENCES}

[1] Asnafi, M. \& Dastgheibifard, S. (2018). A Review on Potential Applications of Unmanned Aerial Vehicle for Construction Industry. Sustainable Structures and Materials, An International Journal, 1(2), 44-53.

[2] Grosso, R., Mecca, U., Moglia, G., Prizzon, F., \& Rebaudengo, M. (2020). Collecting Built Environment Information Using UAVs: Time and Applicability in Building Inspection Activities. Sustainability, MDPI, Open Access Journal, 12(11), 1-15. https://doi.org/10.3390/su12114731 
[3] Chen, Y., Zhang, J., \& Min, B. (2019). Applications of BIM and UAV to construction safety. CSCE Annual Conference, 17.

[4] Vacanas, Y., Themistocleous, K., Agapiou, A., \& Hadjimitsis, D. (2015). Building Information Modelling (BIM) and Unmanned Aerial Vehicle (UAV) technologies in infrastructure construction project management and delay and disruption analysis. Proc. SPIE 9535, Third International Conference on Remote Sensing and Geoinformation of the Environment (RSCy2015), 95350C. https://doi.org/10.1117/12.2192723

[5] Banaszek, A., Banaszek, S., Cellmer. A., Gibert, V., \& Serrat, C. (2019). A Fully Interactive Visualization Method for Building Condition Assessment. IOP Conf. Ser.: Mater. Sci. Eng. 603 022011, 1-10. https://doi.org/10.1088/1757-899X/603/2/022011

[6] Li, C., Shen, L., Wang, H. B., \& Lei. T. (2010). The research on unmanned aerial vehicle remote sensing and its applications. $2^{\text {nd }}$ International Conference on Advanced Computer Control, Shenyang, 644-647.

[7] Mesas-Carrascosa, F. J., Rumbao, I. C., Berrocal, J. A. B., \& Porras, A. G.-F. (2014). Positional Quality Assessment of Orthophotos Obtained from Sensors Onboard Multi-Rotor UAV Platforms. Sensors, 14, 22394-22407. https://doi.org/10.3390/s141222394

[8] Lin, Z. J. (2008). UAV for mapping - low altitude photogrammetric survey. The International Archives of the Photogrammetry, Remote Sensing and Spatial Information Sciences, Vol. XXXVII. Part B1, 1183-1186.

[9] Niethammer, U., Rothmund, S., Schwaderer, U., Zeman, J., \& Joswig, M. (2011). Open source image-processing tools for low-cost UAV-based landslide investigations. International Archives of the Photogrammetry, Remote Sensing and Spatial Information Sciences, Volume XXXVIII-1/C22, 161-166. https://doi.org/10.5194/isprsarchives-XXXVIII-1-C22-161-2011

[10] Wierzbickia, D, Kedzierskia, M., \& Fryskowska, A. (2015). Assessment of the influence of UAV image quality on the orthophoto production. The International Archives of the Photogrammetry, Remote Sensing and Spatial Information Sciences, Volume XL-1/W4, 1-8. https://doi.org/10.5194/isprsarchives-XL-1-W4-1-2015

[11] Fernandez Galarreta, J., Kerle, N., \& Gerke, M. (2015). UAVbased urban structural damage assessment using object-based image analysis and semantic reasonin. Nat. Hazards Earth Syst. Sci., 15, 1087-1101. https://doi.org/10.5194/nhess-15-1087-2015

[12] Torok, M. M., Golparvar-Fard, M., \& Kochersberger, K. B. (2014). Image-based automated 3D crack detection for postdisaster building assessment. Journal of Computing in Civil Engineering, 28(5). https://doi.org/10.1061/(ASCE)CP.1943-5487.0000334

[13] Malihi, S., Valadan Zoej, M. J., Hahn, M., Mokhtarzade, M., \& Arefi, H. (2016). 3D Building Reconstruction Using Dense Photogrammetric Point Cloud. The International Archives of the Photogrammetry, Remote Sensing and Spatial Information Sciences, Volume XLI-B3, 71-74. https://doi.org/10.5194/isprsarchives-XLI-B3-71-2016

\author{
Authors' contacts: \\ Carles Serrat, $\mathrm{PhD}$ \\ (Corresponding author) \\ IEMAE-EPSEB and Dept. of Mathematics, \\ Universitat Politècnica de Catalunya-BarcelonaTECH, \\ Dr Marañón, 44-50, 08028-Barcelona, Spain \\ E-mail: carles.serrat@upc.edu \\ Sebastian Banaszek, PhD \\ Training and Research Center "DroneTechCamp" \\ UI. Jarocka 64/2, 10-699, Olsztyn, Poland \\ E-mail: sebastian.banaszek@banaszekgroup.pl \\ Anna Cellmer, $\mathrm{PhD}$ \\ Dept. of Geoinformatics, \\ The Faculty of Civil Engineering, Environmental Engineering and Geodesy, \\ Koszalin University of Technology, \\ UI. Śniadeckich 2,75-453 budynek E pokój 212-2 E, Koszalin, Poland \\ E-mail: anna.cellmer@tu.koszalin.pl \\ Vicenç Gibert, PhD \\ LABEDI-EPSEB and Dept. of Architectural Technology, \\ Universitat Politècnica de Catalunya-BarcelonaTECH, \\ Dr Marañón, 44-50, 08028-Barcelona, Spain \\ E-mail: vicenc.gibert@upc.edu \\ Anna Banaszek, $\mathrm{PhD}$ \\ banaszek group, \\ Ul. Jarocka 64/2, 10-699, Olsztyn, Poland \\ E-mail: anna.banaszek@banaszekgroup.pl
}

